\title{
The Role of Physical Characteristics in Enhancing Social Interaction and Use of Urban Space (A case analysis of neighborhood center of Soltan Mir Ahmad, Kashan)
}

\author{
Azam Sadat Razavizadeh*, Hamid Majedi and Farah Habib \\ Department of Art and Architecture, Science and Research Branch, Islamic Azad University, Tehran, \\ Iran. \\ *a.razavizadeh@iaukashan.ac.ir
}

\begin{abstract}
The present study investigates the effect of spatial features of urban space on enhancing user-space through increasing social interaction. In recent years, the rate of presence and occurrence of social interaction in public places such as neighborhood centers have been noticeable. This issue can play an important role in recognizing the social relations, in environmental quality, in revealing social life as well as the culture. The present study was done in Sultan-Mirahmad neighborhood. It is considered that legibility, complexity, accessibility, the hierarchy of spatial as well as identifying features affect the occurrence of different usages and the variety of activities during the daily life in the neighborhood. To investigate the role of spatial features, 50 available local residents and newcomers (tourists) were selected and a questionnaire was designed to do the survey. The Cronbach alpha validity came 0.75 . Analyzing the data, three factors were identified including legibility, complexity and accessibility with every factor including some sub-factors. Based on this study, a model can be compiled to show how these three factors interplay in enhancing social interactions. The rate of effectiveness of the factors depends on the various sub-factors that make them up. The results showed that these three characteristics of spatial features are the most important in significantly enhancing the social interaction and use of urban space.
\end{abstract}

Keywords: Neighborhood Centers, Physical Characteristics, Urban Spaces, Social interaction.

\section{INTRODUCTION}

The attendance of people in urban space has been taken into account by environmental science researchers. There is a close relationship between social interactions and environmental physical characteristics which can regard the urban space vital and dynamic along with the attendance of people. Generally, people come to urban space to commute, purchase and interact with one another. The special attributes and environmental physical characteristics can affect these activities.Such activities can also be altered due to the influence of other activities.

In general meaning, the urban space is the reciprocal interaction between and space and behavior. Moreover, it is the most important occurrence space, emergence of daily activities of people and the main center of social relationships. After considering the theoretical foundations through content analysis, the factors of legibility, complexity and accessibility are specified. Then, using questionnaire data, the obtained factors are considered in Sultan Mirahmad neighborhood center. Finally, analyzing the data, the rate of effectiveness of each factor is specified. The obtained results can be used in environment-behavior studies.

\section{MATERIALS AND METHODS}

The present study has a content approach and is a phenomenological research. Having determined the relationship between the variables, this fundamental study aims at compiling a model to explain the relationship between user behavior and urban environment. Using survey method and recognizing the effective factor's space as well as their relationships, the theoretical model is suggested as a neighborhood center to enhance the quality of social interactions in urban space.

50 locals of Sultan Mirahmad neighborhood and the visiting tourists were the population of the study. Before conducting the study, the reliability and validity were calculated. Firstly, the questions and their relationship with the obtained factors were considered by the experts to verify the validity of the questionnaire. Then, using the survey questionnaire data in SPSS Software, the effective factors of the 
suggested model were analyzed. Also, through the variance test of alpha Cronbach, the comparison method and reliability of the sample variance were done.

\section{SOCIAL INTERACTION AND URBAN SPACE}

In a hot sunny day in Downtown Square, pedestrians go along the pavements. People sit on benches and stairs and enjoy drinking a cup of coffee. The peddlers astray around and children go to a strange stature; the groups of workers are talking. The city creates an aura of movement and activity and the people's motion is one of the big landscapes of urban piazzas (Whyte, 1980).

The relationship between environmental design researchers and designers began widely at the start of 1960s (Altman, 1975, 239) and some studies were done on the pedestrian activities and behaviors of people in urban space to promote the quality (Nassar, 1990). Thiel invented a method called "measuring and counting the space". In his studies on Japanese samples, the physical shapes perceived by speed and direction change were ordered (Thiel, 1961:34). This method which is among the most complicated and comprehensive methods is used to record and analyze the features of pedestrian spaces with low speed. Analyzability is the most outstanding feature of this method where high number of conventional signs is determined for special spatial features and then the passerby's behavior is analyzed based on them. Thiel's main purpose was to find conventional signs for identifying all space characteristics like crowdedness or retreating to create a common language for designers (Bahrainy, 2009, 237).

For Cullen, the vision of the city was the art of relationship. There were three factors influencing the sensory experience include:

The first factor is visioning which is related to the experience of walking in the city with the same pace where some scenes in the collection of movements and decoding known as sequential view is resulted. In other words, the experience of the person from place is caused by sequential views. The second factor is place referring to physical relationship of human body with environment related to person's reaction to positions such as far, near, closed and open. The third factor is content dealing with the city texture which is color, scale, style and peculiarities (Cullen, 1976; Tavallaei, 2008.92).

Vision is the most important of the three introducing the dynamic experience against the static experience of looking at the city. Cullen's method is based on visual analysis and identification of visual characteristics of the city vision in which viewer's position while moving is important. In other words, to understand the urban phenomenon, the view of the moving observer is important. These features including complexity and variety of the perceived data was considered later on in proportion and urban gestalt studies and semiotics in architecture studies like Venchuri and Jenks studies (Gosling, 1996).

In 1981, Kevin Lynch, in "The theory of good city form" suggested five main axes for spatial form of the cities. One of them is proportion which means the adequacy of behavioral contexts. According to Lynch, proportion is a settlement where the size of spatial and temporal model is matched with the common behavior of the users and residents. In other words, proportion is correspondence between form and function in behavioral contexts and behavioral circuits. (Lynch, 1981).So, it can be concluded that proportion is closely related to culture. Lynch (1981) considered two ways for considering the proportion or behavior interpretation: first, observing people while doing something and recording with cassette or taking photo and, second asking the users. Mental representation of environment is called cognitive map. Most of the researchers believe that our cognitive maps from bigger environment are a combination of spatial information obtained from maps, direct personal experience and other types of sources. Most of studies on cognitive maps are related to urban cognition. According to Lynch, legibility is one of the most important urban characteristics referring to easy identification of city aspects, its organization in a plan and easy reminding. Most people prefer environments which are easily red and perceived quickly (Mac Andrew, 1992, 45-47). Lynch studies showed that people consider five key aspects when making a mental image of a city. Path is movement ways and transfer passages. Edges are linear elements which shouldn't necessarily be ways but separating lines of different parts of environment. Districts are the mean of bigger parts of a city and a person can be there. Nodes are strategic points in a city for transferring and travelling to other parts. Landmarks are physical buildings, statues or fountains which are peculiar, outstanding and important. The guides are things used when showing a way.

William, H. Whyte (1980) observed that how people use public space. He observed that using the space out of peak hours is the best sign to people's preference to use the space. When a square is crowded, people sit everywhere they find instead of the place they want actually. A little later, some parts get vacant 
while other are still getting used (Carmona, 2005.334). in 1981, Donald Appleyard, the professor of vision architecture and urban-regional planning at University of California published a book titled "Habitable Streets" in which he presented the practical and real codes for analysis and evaluation of buildings' quality and the ways to make habitable and safe streets. Then, in 1982, an international symposium called "Streets are owned by public" was hold in Washington University where some main issues for research were suggested such as investigating the effect of street design on people's movement and other behaviors, revision of standards of street design, considering the possibility of machine and man co-existence to create a more proper place for living (Bahrainy, 2009.25).

So, understanding the positive and negative points of a behavioral environment and that the environment is proper for whom is not an easy task. Alexander and his followers kept silent in this case and their work can't be considered as a theory but their idea is a collection of scientific methods which knowing them is useful (Lawson, 2001.238). We find a kind of ideology in our nature which has a mechanical nature. What is probably called logical-mechanical image, either believed or not, awarded or not, has penetrated and deposited in our ideology which influences our behavior (Alexander, 1979.11).

\section{PHYSICAL CHARACTERISTICS}

Regarding the proposed theories, social activities and interactions are the basics of defining a dynamic urban space. Also, public places such as neighborhood centers have a main role in creating social interaction in neighborhood scale and promoting the quality of urban space. Regarding the theories, the model of pedestrian behavior with visibility is based on the fact that instinctively human move toward a direction where they can find more movement in a specified time. This is natural visual perspective which is a combination of visual elements influencing human behavior. We can consider this feature as the conditions of natural movement. In places where going from one perspective to another or looking around is considered natural interaction, understanding this distinction is important. To move around and going toward thinking a natural movement, a user needs recognizing the things as the difference with the environment. The user should only distinguish that there is an environment where discovery is related to moving in that path. Hiller et al showed that lots of pedestrians' moves happen along with the lines of perspectives. The more direct this line (in relation to other lines), more movement happens in it. So, the theory of natural movement is based on this fact that person's movement is made by positioning and environment combination in the absence of change and environment condition.

The relationship between composition and surface is direct. Composition walk able surface have both the same value as producers of possibility (Hillier et al, 1992). Rapoport concern was focused more on researching the bonds between culture and the society. Most of his studies are on environmental behaviors and urban planning. Habits, manners, roles and behaviors are formed based on the cultural base of every society. Urban space depends on mental space which is considered distinctive of objective space and a special aspect of psychological space. Behavioral and psychological spaces are in relation with cultural spaces. They are classified by different groups and take various territories (Rapoport, 1982. 3).

Assessment of culture is seldom undertaken and often dismissed as purely anecdotal in comparison with the hard evidence offered by established economic and physical compact evaluations. (Garacia, 2005). So, physical characteristics have important role in enhancing urban space quality.(Table1) It seems that these features can increase social interactions. The suggested model based on the proposed theories showed that legibility, complexity and accessibility can be identified as factors of physical characteristics. After recognizing the relationship between effective factors, the effectiveness of each of these factors was assessed through a questionnaire.

Table 1: Physical characteristics of urban space

\begin{tabular}{|c|c|c|}
\hline Theoretician & Focus & $\begin{array}{c}\text { Physical characteristics } \\
\text { of urban space }\end{array}$ \\
\hline $\begin{array}{l}\text { Thiel } \\
(1962)\end{array}$ & $\begin{array}{l}\text { Measuring and } \\
\text { counting the } \\
\text { space } \\
\text { Regulating } \\
\text { physical form } \\
\text { while moving } \\
\text { Putting } \\
\text { conventional } \\
\text { signs for } \\
\text { analysis }\end{array}$ & $\begin{array}{l}\text { Easy accessibility } \\
\text { for all } \\
\text { - } \quad \text { Using natural } \\
\quad \text { elements } \\
\text { - } \quad \text { Invitation } \\
\text { - } \quad \text { Encapsulation } \\
\text { - } \quad \text { Spontaneity }\end{array}$ \\
\hline $\begin{array}{l}\text { Cullen } \\
(1976)\end{array}$ & $\begin{array}{l}\text { The art of } \\
\text { relation } \\
\text { Visioning with } \\
\text { sequential } \\
\text { sequential }\end{array}$ & $\begin{array}{ll}\text { - } & \text { invitation } \\
\text { - } & \text { Visual } \\
& \text { continuity }\end{array}$ \\
\hline
\end{tabular}




\begin{tabular}{|c|c|c|}
\hline & $\begin{array}{l}\text { Decoding the } \\
\text { visions } \\
\text { Person's } \\
\text { reaction to } \\
\text { positioning }\end{array}$ & \\
\hline $\begin{array}{l}\text { Lynch } \\
\text { (1981) }\end{array}$ & $\begin{array}{l}\text { Proportion: the } \\
\text { size of spatial } \\
\text { and temporal } \\
\text { model with } \\
\text { behavior } \\
\text { Correspondence } \\
\text { between form } \\
\text { and function }\end{array}$ & $\begin{array}{ll}\text { - } & \text { Positioning of } \\
\text { identifiable } \\
\text { places } \\
\text { - } \quad \text { Visual } \\
\text { continuity } \\
\text { - } \quad \text { Easy } \\
\text { accessibility } \\
\text { for all }\end{array}$ \\
\hline $\begin{array}{l}\text { Whyte } \\
\text { (1980) }\end{array}$ & $\begin{array}{l}\text { The peak time } \\
\text { of using space } \\
\text { A place for } \\
\text { sitting }\end{array}$ & $\begin{array}{ll}\text { - } & \text { Spatial } \\
& \text { proportion } \\
\text { - } & \text { Using natural } \\
& \text { elements } \\
\text { - } & \text { Visual } \\
& \text { continuity }\end{array}$ \\
\hline $\begin{array}{l}\text { Rappaport } \\
\text { (1982) }\end{array}$ & $\begin{array}{l}\text { Cultural norms, } \\
\text { distinctive } \\
\text { behavioral } \\
\text { habits from } \\
\text { objective space }\end{array}$ & $\begin{array}{ll}\text { - } & \text { Positioning of } \\
\text { identifiable } \\
\text { places } \\
\text { - } \quad \text { Invitation }\end{array}$ \\
\hline
\end{tabular}

Source: Researcher

So, perceptive aspect of environment plays a significant role in behavioral models. In analyzing the social interaction occurred in urban space, this step can be noticed that how recognition of an environment is first obtained.

\section{CASE STUDY}

To study the topic, sultan Mirahmad neighborhood in Kashan was considered first. This neighborhood center is among the dynamic spaces with indigenous people and small number of migrants. Among the features of this area are historical houses of Tabatabaeis, Broujerdies, sultan Mirahmad bath, and Sultan Mirahmad's son. The propinquity of the edges of the neighborhood texture with the main streets of Kashan has provided the connection and continuity with the center of the city (Naraghi, 1986). In the street close to neighborhood center, different activities have formed which can be considered as movement goals and people attendance in the neighborhood. In passages, children can be observed playing in the evenings or after school. Old passages which are appropriate with the climate provide the movement of people in hot days and environmental comfort can be considered as a significant feature. Also, valuable historical elements can be considered as a historical identity and as an attractive motivation for attracting the tourists. The existence of desirable sequential view in the paths and internal passages of the area can provide the motivation for the pedestrians to attend and move in the texture.

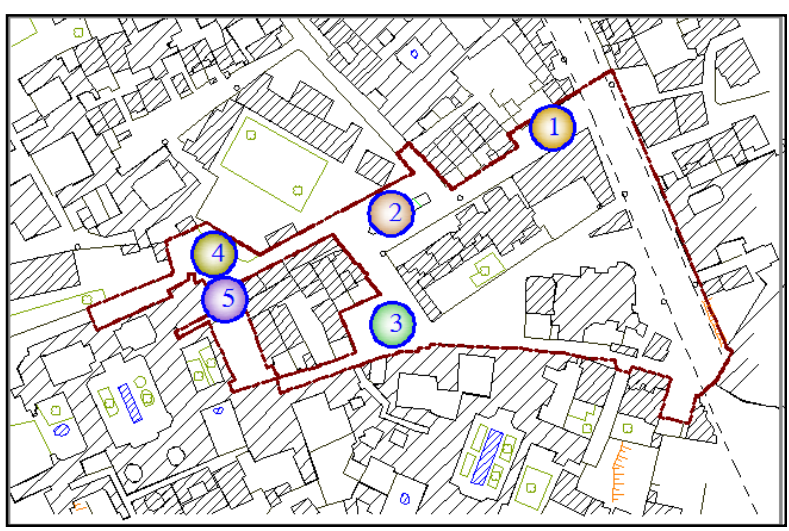

Figure 1: Center of Sultan Mirahmad neighborhood. Resource: Kashan municipality

First a questionnaire was developed and the questions were targeted regarding the physical characteristics obtained from theoretical studies. Then, it was distributed among a panel of experts. The relationship between the questionnaire goals and the content of physical features were considered (table 2). The validity of the questionnaire was verified. The measured characteristics were based on the considered goals and the questions were designed based on them.

Then, using the survey data, the reliability of for considering the relationship between the obtained variables and discovering the meaningful relationships was calculated through SPSS Software to find the effective factors in modeling the research issue. So Cronbach alpha reliability was used to show the same results when repeating the survey. So, the value of sample variance comparison was done systematically. Regarding the obtained value of Cronbach alpha $(75 \%)$, it is considered acceptable.

Table 2: The Relationship Between Questionnaire's Goals and Content

\begin{tabular}{|l|c|c|}
\hline $\begin{array}{c}\text { Content } \\
\text { Questionnaire's goals }\end{array}$ & $\begin{array}{c}\text { Perceptiv } \\
\text { e-physical }\end{array}$ & $\begin{array}{c}\text { Physical- } \\
\text { semantic }\end{array}$ \\
\hline Visual continuity & 1 & \\
\hline Simultaneity & & 2 \\
\hline Easy accessibility for all & 3 & \\
\hline Encapsulation & 4 & \\
\hline The space in public view & & 5 \\
\hline invitation & & 6 \\
\hline
\end{tabular}




\begin{tabular}{|l|c|c|}
\hline Identifiable places & 7 & \\
\hline using natural elements & 8 & \\
\hline Spatial proportion & & 9 \\
\hline
\end{tabular}

Source: Researcher

\section{RESULTS \& DISCUSSION}

After collecting the data, factor analysis was done through regulating the matrix of raw data. To this end, in the first step after extracting the underlying objectives from the related studies, the primary matrix of information was made. The matrix includes 9 goal features as matrix rows and two physical dimensions as the columns of the matrix (physical-perceptive) \& (physical-semantic). Three related factors to underlying objectives and research hypotheses were obtained which are legibility, complexity and accessibility. In analyzing the data, first nonorthogonal confirmatory factor analysis was directly done on physical characteristics section of the questionnaire using elements (table 3 ). According to the questions loaded on each of the factors, a name was selected for each factor. In the next stage, the relationship between the factors and physical characteristics was investigated through Pearson correlation.

Table 3: The introduced elements of factor analysis and physical features and their explained variances

\begin{tabular}{|c|c|c|c|c|c|c|}
\hline \multirow[t]{2}{*}{$\begin{array}{l}\text { fac } \\
\text { tor }\end{array}$} & \multicolumn{3}{|c|}{$\begin{array}{l}\text { The special primary } \\
\text { value for each factor }\end{array}$} & \multicolumn{3}{|c|}{ Factor load } \\
\hline & $\begin{array}{l}\text { Val } \\
\text { ue }\end{array}$ & $\begin{array}{l}\text { Vari } \\
\text { ance }\end{array}$ & $\begin{array}{c}\text { Cumul } \\
\text { ative } \\
\text { percen } \\
t\end{array}$ & $\begin{array}{l}\text { Val } \\
\text { ue }\end{array}$ & $\begin{array}{c}\text { Vari } \\
\text { ance } \\
\text { perce } \\
\text { nt }\end{array}$ & $\begin{array}{c}\text { Cumul } \\
\text { ative } \\
\text { percen } \\
t\end{array}$ \\
\hline 1 & 2.4 & 29.5 & 29.5 & 2.4 & 29.5 & 29.5 \\
\hline 2 & 1.6 & 21.4 & 50.9 & 1.8 & 21.4 & 50.9 \\
\hline 3 & 1.4 & 17.2 & 61.8 & 1.4 & 17.2 & 61.8 \\
\hline 4 & $\begin{array}{c}0.7 \\
4\end{array}$ & 7.4 & 75.5 & & & \\
\hline 5 & $\begin{array}{c}0.6 \\
5\end{array}$ & 6.5 & 82.0 & & & \\
\hline 6 & $\begin{array}{c}0.5 \\
4\end{array}$ & 6.1 & 88.1 & & & \\
\hline 7 & $\begin{array}{c}0.4 \\
6\end{array}$ & 5.8 & 93.9 & & & \\
\hline 8 & $\begin{array}{c}0.3 \\
1\end{array}$ & 4.4 & 98.3 & & & \\
\hline 9 & $\begin{array}{c}0.2 \\
6 \\
\end{array}$ & 1.7 & 100 & & & \\
\hline
\end{tabular}

Source: Researcher
Regarding Table 3 in factor analysis, three hidden variables were resulted which are factors one to three having special value more than one. Totally, they explain $68.1 \%$ of the variance of physical features. The three variables were named after matching with questions (table4) as legibility, complexity and accessibility.

Table 4: The extracted factors and the explained variance of each measure for factor

\begin{tabular}{|c|c|c|c|c|}
\hline \multirow[t]{2}{*}{ Row } & \multirow[t]{2}{*}{ Extracted features } & \multicolumn{3}{|c|}{ Factor } \\
\hline & & 1 & 2 & 3 \\
\hline 1 & \multicolumn{4}{|c|}{ Legibility } \\
\hline 1.1 & $\begin{array}{l}\text { Visual continuity } \\
\text { (viewing people in } \\
\text { places) }\end{array}$ & 0.62 & & \\
\hline 1.2 & $\begin{array}{l}\text { Space in public } \\
\text { view (neighborhood } \\
\text { accumulation }\end{array}$ & 0.54 & & \\
\hline 1.3 & $\begin{array}{l}\text { Positioning of the } \\
\text { identifiable places } \\
\text { (a place for social } \\
\text { interactions, } \\
\text { talking, sitting }\end{array}$ & 0.72 & & \\
\hline 2 & \multicolumn{4}{|c|}{ Complexity } \\
\hline 2.1 & $\begin{array}{l}\text { Encapsulation (the } \\
\text { motivation to be in } \\
\text { the space) }\end{array}$ & & 0.66 & \\
\hline 2.2 & $\begin{array}{l}\text { Spontaneity } \\
\text { (causing motivation } \\
\text { for movement) }\end{array}$ & & 0.57 & \\
\hline 2.3 & $\begin{array}{l}\text { Spatial proportion } \\
\text { (privacy with space, } \\
\text { be comfortable) }\end{array}$ & & 0.73 & \\
\hline 3 & \multicolumn{4}{|c|}{ Accessibility } \\
\hline 3.1 & $\begin{array}{l}\text { Invitation (the } \\
\text { attraction to be in } \\
\text { the space) }\end{array}$ & & & 0.55 \\
\hline 3.2 & $\begin{array}{l}\text { Easy accessibility } \\
\text { for all (movement } \\
\text { ease to reach } \\
\text { destination) }\end{array}$ & & & 0.60 \\
\hline 3.3 & $\begin{array}{l}\text { Using natural } \\
\text { elements (climatic } \\
\text { comfort in user's } \\
\text { positioning in the } \\
\text { space) }\end{array}$ & & & 0.53 \\
\hline
\end{tabular}

Source: Researcher

Pearson correlation was used to investigate the relationship between the variables (Table5). 
Table 5: Pearson correlation. Physical characteristics and social interactions

\begin{tabular}{|l|l|l|l|c|}
\hline $\begin{array}{c}\text { Physical } \\
\text { Components }\end{array}$ & Mean & SD & R & Sig \\
\hline Legibility & 2.76 & 0.70 & -0.190 & $<0.001$ \\
\hline Complexity & 2.66 & 0.55 & -0.197 & $<0.001$ \\
\hline Accessibility & 2.68 & 0.53 & -0.192 & $<0.001$ \\
\hline
\end{tabular}

It was shown that there is a relationship between legibility and observable places so that correlation coefficient shows more agreement in effectiveness of social interaction. Also, physical characteristics and accessibility increase social interaction.

\section{CONCLUSIONS}

The results showed that there is a meaningful relationship between social interaction and physical components. Also, when physical characteristics are appropriate, the capacity of social interactions increase in the form of values, and socio-cultural norms and bonds. Regarding that the participants of this study were both local and new comers, these features are separate from the concept of familiarity with environment (previous experience). So, promoting these characteristics, the possibility of social relationships between the residents of the neighborhood and social interaction among the users of the space can be provided. To this end, using the plans to support the interactions is related to physical features. As shown, there were three effective factors in enhancing the quality of social interactions and attendance of the users in urban space. The results showed that there is a relationship between legibility, complexity and accessibility which are related to physical characteristics.

\section{ACKNOWLEDGEMENT}

This article was extracted from the author's $\mathrm{PhD}$ thesis,"Explanation of Behavior and Urban Space by Phenomenological Approach In Historical Texture of Kashan ,Iran" under supervision of:Dr.Hamid Majed and Dr,farah Habib,in department of Art and Architecture,Science and Research Branch,Islamic Azad University,Theran,Iran.

\section{REFERENCES}

Alexander, C.(1979)"The Timeless Way of Building", Oxford University Press, London.
Altman, I. (1975)"The Environment and Social Behavior", Brooks/Cole Publishing Company.

Bahrainy, H.(2009)"Analysis of Contemporary Urban Design Theories, Vol.1:From Late 19th Century to 1970's(A.D.)"Tehran University Press, Tehran.

Carmona,M.Heath,T.Oc,T.Tiesdell,S.(2005)"PublicPlac es,UrbanSpaces,The Dimension of Urban Design" Architectural Press, An imprint of Elsevier.

Cullen, G. (1976) "Townscape", New York ,Van Nostrand Rienhold.

Garcia,B.(2005).Deconstructing the City of Culture: The Long-term Cultural Legacies of Glasgow 1990.Urban Studies Journal . May 2005 vol.42 no.56, 841-868,doi:10.1080/00420980500107532.

Gasling,D.(1976)."Gordon Cullen :Visions of Urban Design", Academy Editions, London.

Hillier,B.,Penn A Hanson J, Grajewski T,Xu J,(1992),Natural Movement: or, Configuration and Attraction in Planning B: planning and design, 19,29-66.

Kashan Comprehensive Plan Report (2009) Naghshe Jahan Pars Consultant Engineers.

Lawson,B.(2001)"The Language of Space "translated by: Einifar, Alireza; Karimiam, Foud, Tehran University Press, Tehran.

Lynch, K. (1960), The Image of the City ,Cambridge,MIT Press.

Nasar, JL \&Yurdakul, R(. 1990). Patterns of behavior in urban public spaces: A case study. Journal of Architectural and Planning Research, 7, 71-85

Mac Andrew,F.(1992)"Environmental Psychology, Brooks/Cole Pub Co .

Naraghi, H.(1986)"Kashan Social History", Cultural and Scientific Press, 2nd.Impression.

Rapoport, A.(1982)"The meaning of the built environment : Anonverbal Communication Approach" translated by:Dr.Habib, Farah,(2012) Information and Communication Technology Organization Press.

Thiel, P.(1961)A Sequence-experience notion for Architectural and Urban Space, Town Planning Review ,32,33-52,Online Date: Tuesday, April 27,2010,www.metapress.

Tavallaei, N.(2008)"Integrated Urban Form"Amirkabir Publishing Corp, Tehran,Iran.

Whyte, W. (1980)"Social Life of Small Urban Space", Can Sevation Foundation. 